\title{
PLANNING FOR A SUSTAINABLE COMPACT CITY: A WAY FORWARD
}

\author{
JAYESHKUMAR MAHESHKUMAR BHAGWAT \& VARUVEL DEVADAS \\ Department of Architecture and Planning, Indian Institute of Technology (IIT), India
}

\begin{abstract}
Cities are the engines of economic growth. The concentration of population in urban settlements is a result of the centralization of resources and triggers in-migration. Sprawl, congestion, increasing densities, and social exclusion are the major urban challenges faced by the cities of the developing world. At this juncture, it is important for planners to address these issues to make the cities liveable. The compact city concept is one of the concepts to address similar problems faced by the developing world. Implementation of the compact city concept is limited to an increase in density, redistribution of density, implement transit-oriented development schemes, and mixed uses of the land resource in existing practices. The compact city concept is widely discussed and debated due to its benefits and costs with respect to sustainable urban development. This paper aims to conduct an in-depth study on the sustainable compact city concept by taking into account the literature available from various contexts around the world. The paper investigates the existing methodologies and proposes the optimal methodology for sustainable compact city planning.
\end{abstract}

Keywords: methodology, sustainable compact city, density, urban system, urban challenges.

\section{INTRODUCTION}

Cities serve as the powerhouses of the economic aspirations of people. The concentration of economic activities leads to accessibility to employment, quality education, medical facilities, and ultimately a superior quality of life. The in-migration of people in the cities leads to various challenges, which may include accessibility to infrastructure, an increase in pollution, and sprawling urban settlements. This makes it necessary to confine the cities within a specific limit and promote compact growth.

\subsection{Compact city}

Dantzing and Saaty are considered to be the founders of the compact city concept. They defined three major characteristics of compact city, and are: (i) with respect to urban morphology, the compact city has high-density residential areas, reduced reliance on motor vehicles, and clear boundaries with neighbouring regions; (ii) spatially, the compact city is characterized by mixed land use and a high diversity of lifestyles; and (iii) the social functions of the compact city include social equality, self-sufficiency of daily life, and independent regional management (Dantzig and Saaty [1]).

Compact City is comparatively a newer concept and is promoted by the international organizations like the UNEP, World Bank, UN-Habitat and OECD (Holman et al. [2]). Cities in the post-industrial period around the world show synonymous characteristics. This includes a divide in the society, clustering of activities, and an increase in vehicular dependency. Such characteristics promoted urban sprawl, increased socio-economic segregation, and increased pollution. In the process to enhance people's interaction and social inclusion bringing people closer in the key. The compact city is one such concept to promote social inclusion. Mixed-use is another predominant factor, which increases the usage of space. A mix of uses promotes an increase in the densities. This in response to help in the promotion of walkability and reducing vehicle dependency in the city. Thus, a compact city 
is one of the solutions for the development of social inclusion, reduces pollution, and ultimately promote a better quality of life.

\subsection{Sustainable development}

Sustainable development is a prime concern in all spectrums of human life. It is a broad term applied to various fields like industrial production, health, finance, economics, etc. There are various definitions of Sustainable Development. The authors have taken a brief review of some definitions. Sustainable agriculture is a system that can evolve indefinitely toward greater human utility, greater efficiency of resource used and a balance with the environment, which is favourable to humans and most other species (Harwood [3]). Sustainable development involves devising a social and economic system, which ensures that these goals are sustained, i.e., that real income rise, that educational standards increase, that the health of the nation improves, that the general quality of life is advanced (Pearce et al. [4]). Agricultural sustainability is defined as the ability to maintain productivity, whether as a field or farm or nation. Where productivity is the output of the valued product per unit of resource input (Conway and Barbier [5]). Sustainable development is concerned with the development of a society where the costs of development are not transferred to future generations or at least an attempt is made to compensate for such costs (Pearce and Atkinson [6]. The most prominent and universally accepted definition of sustainable development is given by the Brundtland Commission, "Sustainable development is a development that meets the needs of the present without compromising the needs of future generations to meet their own needs" (WCED [7]). There are three basic components of sustainable development namely, social sustainability, economic sustainability and environmental sustainability. In various connotations, sustainable development is predominantly a mechanism by which the available resources could be made available and accessible to all.

\subsection{Sustainable compact city}

The compact city contains characteristics like mixed-use, height density, social inclusion and accessibility. These are the solution to the diverse range of problems the cities of the developing countries are facing. Sustainability, which includes environmental, social and economic components if added to the concept of a compact city, the benefits of compact city planning can be enhanced. This includes the trade-offs which need to be balanced in order to achieve the desired amount of compact city features by maintaining economic, environmental and social sustainability. In the subsequent parts of the paper, the existing research published related compact city are reviewed and methodologies (if any) for the planning for a holistic sustainable compact city. Finally, the authors evolve to an optimal methodology for sustainable compact city planning.

\section{LITERATURE}

In the review of literature, the authors broadly cover the various components in which research pertaining to compact city planning is conducted. The research related to compact city planning is emphasized and limited to certain components, for example, high density, and environmental impacts caused by car dependency. The various streams in which research is undertaken is shown in (Fig. 1) The components like social inclusion and mixed-use development are inadequately addressed in terms of research (Boyko and Cooper [8]). The components addressed are predominantly qualitative in nature and quantitative analysis is minimal. 


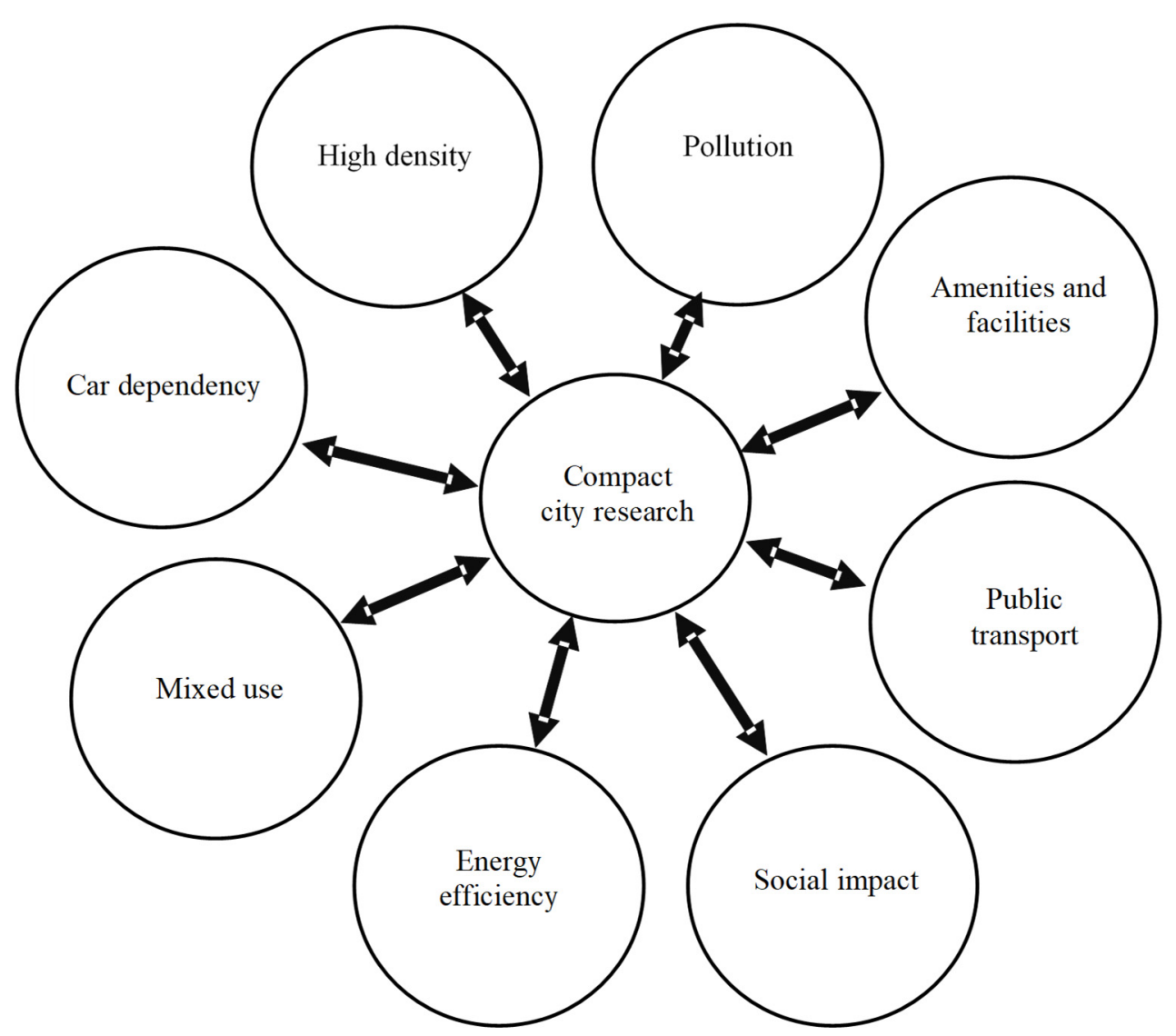

Figure 1: Research related to compact city planning. (Source: Authors, 2020.)

Cities in the developed world have made policies centric to compact city planning and have gain results. Researchers observe that the cities like Melbourne, London, Amsterdam, etc. have successfully harvested the potential in creating compact cities. It is also analysed that the success of a compact city lies in the lifestyle, and choice of people to stay in and move back to urban areas in comparison with the suburban neighbourhoods [2], [9]-[11]. The compact city could be instrumental in reducing urban sprawl, vehicular pollution and combat environmental degradation in the urban system [8], [9], [12].

The value of urban spaces increases with an increase in urban density [13], [14]. The cost of construction increases with the increase in height of the structure, but in certain circumstances, it is economical to promote high density [15], [16]. Certain policies related to compact urban form promote an increase in the value of urban spaces (Hilber and Cheshire [17]). Compact city concept reduces the distance between work and place. It reduces the money spent on travel on one hand, and it may increase the time required for travel on the other [14], [18]. The use of public transport becomes more viable and promotes accessibility [19], [20].

Services and amenities are influenced as a result of compact city reforms. Public transport becomes more effective, reliable and user-friendly with higher urban density [21], [22]. On 
the other hand, making water available; and collection and disposal of waste is a major challenge in high-density areas, where streets are narrow (Troy [23]). Mixed land use as a result of the compact city results in a clustering of amenities like educational institutions; financial institutions; hotels and restaurants, etc., which reduces the distance between services and consumers [12], [15]. It increases the variety of services available, and thereby consumption of services and amenities in the area (Bonfantini [24]). Thus, making amenities, services or infrastructure available and accessible is a challenge in the planning of compact city development.

Social equity as a result of a compact city is debated by researchers. A group of scholars claim that it promotes social equity (Burton [12]). While others claim that such a tall building can lead to segregation as they are viable at high rents (Radberg [25]). Similar contradictions are observed in the case of the impact of high-density compact city planning on crime. High density leads to more crime, as street intersections, mass transit stations, and other elements associated with density may lead to crime and clustering of crime [12], [26]. It is claimed that density facilitates light design, which will avoid crime-related activities while others add that density increase may lead to "eyes on the street", this will reduce crime in a compact city [27]-[29]. So, social equity and crime are related to a compact city but with contradicting results.

Environmental impacts and compact city planning are closely associated. High urban density results in reduced open spaces and biodiversity in the city but promotes more opportunity of green spaces in the suburban areas [18], [20], [30]. The compact city will result in less car dependency, fewer trips and reduced carbon emission as a whole [31]. However, the concentration of traffic in the inner-city area can result in more emissions and noise pollution (Troy [23]). Mix use reduces the trip length and carbon emissions. It is also claimed by a group of researchers that, energy efficiency in a compact city is more as compared to low-density urban development (Gordon and Richardson [32]). Walkability, cyclability, and public transport as a result of compact city planning result in a reduction in environmental impacts [12], [18]. Environmental consequences of the compact city are considered to be positive, as a result, the health of people benefits due to such a city planning approach. Other groups of researchers claim that, due to the concentration of emissions, the negative impact of the compact city on health is more adverse [12], [23]. So, environmentally compact cities are more functional as compared to low-density cities. Thus, the literature on the sustainable compact city is conducted in isolation, and a holistic approach to address the sustainability component associated with a compact city to build a full picture is missing in contemporary research. Therefore, it is necessary to evolve an optimal methodology to access the planning and development of the sustainable compact city.

\section{EXISTING METHODOLOGIES FOR THE PLANNING OF A SUSTAINABLE COMPACT CITY}

The methodologies proposed for the planning of sustainable compact city are limited to only specific links between compact city components and sustainable development components.

The compact city components and relation with social equity are analysed by researchers. Here the researcher had firstly defined the term social equity, later they identified the possible social equity effects of compact city planning which include better access to facilities, poorer access to urban greens, better job accessibility, better public transit, more possibility to walk and cycle, reduced domestic living space, poorer health, reduced crime, lower social segregation, and lack of affordable housing. In this methodology, a comparative investigation was undertaken in the selected cities. Data were collected and analysed qualitatively through number measures and statistical tests (multivariant analysis). Various indicators related to 
above mentioned possible social equity effects of the compact city were used for the study (Burton [12]).

In a research, compact city implication on urban environment (green spaces) is analysed. In the methodology, the study area was determined, the variables for the compact city and sustainable development measurements were identified, and the housing price to income ratio is determined. Methods like principle component analysis (PCA) and Geographically weighted regression (GWR) were employed as a part of the methodology [33], [34].

The difference between the theoretical and conceptual framework for measuring urban sustainability in relation to compact and other urban forms were discussed by the scientists in Iran. In their research, the indicators are identified for the research, the techniques to measure sustainability are discussed, an integrated framework was developed by combining domain-based framework and goal-based framework, for measuring urban sustainability for different forms of urban settlements (Masnavi [35]).

Research on sustainable urban form as a result of a compact city in China provides the cost-benefit-based approach. In this methodology, the efficiency, availability of facilities, public transport, resource, and energy consumption were studied for environmental quality. A connection between urban compaction and environmental quality was established as a result of this research (Chen et al. [36]). Another set of researchers discuss the qualitative and quantitative attributes of sustainable compact city planning in the context of Hong Kong (Coorey and Lau [37]).

Lin and Yang [38] provide a holistic approach to plan a sustainable compact city. The cities from Taiwan were selected for the investigation. The weighted least-square is employed in it. The components of the compact city and sustainable development are accounted but this approach is very limited to context-specific, and not a methodology, which could be easily replicated in various circumstances to plan sustainable compact cities.

\section{SYSTEM CONCEPT}

A system functions as a whole with the interaction of several sub-system. All the subsystems of the system are interlinked and interdependent to each other, and forming a system. Even if one of the system defunct, or partly functions or functions with higher degree (taking a lead role) during its function, its effects can be visualized in the entire system over a period of time. Sometime, the system may not function at all while in some cases the system may function, but with lot of disturbances or the smooth functioning of the system may be paralyzed (Devadas and Kumar [39]).

An urban system is a purely dynamic system consisting of physical, social, economic, ecological, environment, infrastructure, and institutional subsystem as shown in (Fig. 2). Each subsystem comprises of certain elements as follows:

- Physical subsystem: This subsystem majorly focuses on land and its associated resources including water, flora, fauna, and minerals. It also consists of land use patterns, topological features, climatic conditions, and their functions.

- Social subsystem: Social subsystem deals with population and its function. Population is a major determinant in the planning process of any urban system. The population comprises various characteristics like sex, age, education, occupation, employment, socioeconomic status, culture, religion, and caste, etc.

- Economic subsystem: The economic subsystem comprises of the role of primary, secondary, tertiary sector in the urban economy, and their functions. 
- Ecological subsystem: Biotic and abiotic components function together as an ecological system. It consists of the number and types of birds, animals, humans, and trees.

- Environment subsystem: It deals with not only consists of the built environment but also the social, economic and political environment and their functions.

- Infrastructure subsystem: It is a physical framework of services, facilities and amenities for the smooth functioning of an urban system.

- Institutional subsystem: The authorities, organizations and local bodies that govern, manage and maintain the urban system are included in this subsystem.

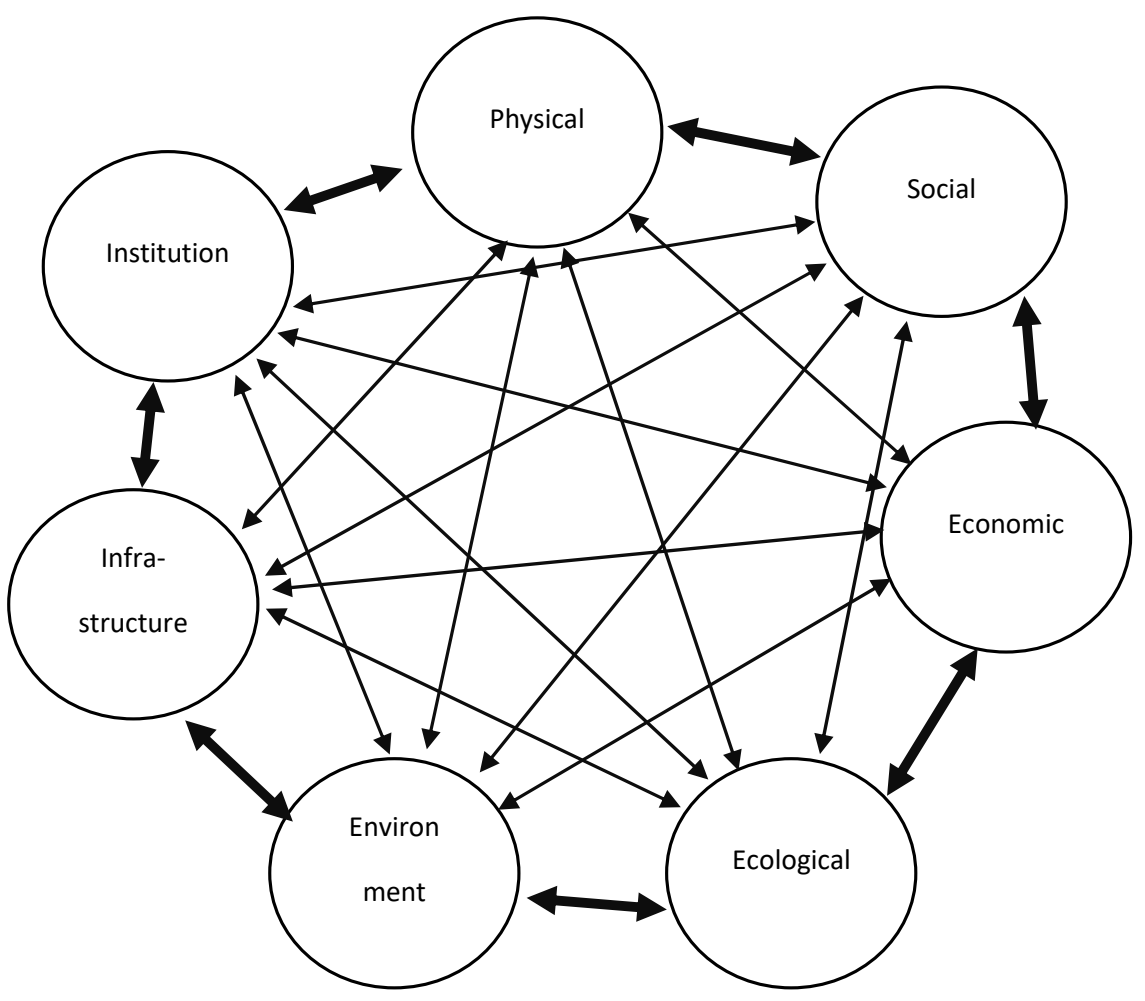

Figure 2: Urban system and its subsystems. (Source: Authors, 2020.)

\section{PROPOSED METHODOLOGY FOR THE PLANNING OF \\ A SUSTAINABLE COMPACT CITY}

It is evident from the literature that the planning process of the sustainable compact city lacks a holistic optimal methodology. The existing methodologies address only the limited components of sustainable development and compact city planning. The methodology proposed in the present research will function as a guiding path in the process of planning a sustainable compact city.

The optimal methodology, shown in (Fig. 3) comprises of the following steps:

- Preliminary literature review: This part includes the review of existing literature, which provides a base for the study to be undertaken. 
- Identification of problem: Identification of problems would be drawn from the preliminary literature review undertaken in the previous steps.

- Defining objectives: The objectives of the study will include the checklist of assessments to be performed in the research.

- In-depth literature review: The in-depth focused literature review will help to streamline the scope and give insights into the work undertaken on the specific subject.

- Theory, hypothesis, and concept: The theoretical understanding will promote the development of the research hypothesis.

- Studying the existing scenarios: The study of existing scenarios will help to develop the profile of the area under study.

- Collection of data and survey: Secondary data by means of policy documents, reports, etc., could be collected. On the other hand, the household survey could be done for primary data collection.

- Analysis: The analytical tools, such as computer hardware, software, code sheet may be employed for data processing and analysis.

- Analytical techniques: Analytical techniques such as, correlation, multiple regression, etc., may be employed for identifying the control parameters, which decide the function of the system.

- Formulation of system dynamics model: To plan a sustainable compact city, operations research model, system dynamics model, socio-econometric model, geographic information system model, may be developed and employed based on the requirement. System dynamic models must be employed to understand the function of the system.

- Model validation: The developed models should be validated. Such models can be used for the application after analysis.

- Forecasting the model: The validated model is used for forecasting based on the requirements of the research.

- Application of model: The validated model is applied to arrive at the desired results.

- Results and discussion: The results of analysis like literature analysis, survey analysis, and model analysis would be discussed in detail.

- Findings: The plausible findings evolved as a result of discussions would be documented.

- Evolving policy guidelines: Policy guidelines would be formulated based on the findings.

- Plan and recommendations: Plausible recommendations should be proposed to develop a sustainable compact city.

\section{CONCLUSION}

Compact city planning is a newer concept. It is debated by the researchers at various levels and hence indicates an opportunity to evolve. Sustainable development is another major concern for city planners and policymakers. It is the only key to maintain the social, economic, and environmental balance of the urban system. The integration of sustainability and compact city concepts could act as a functional one-point solution to solve the challenges faced by the cities around the world. Developing a holistic methodology for sustainable compact city planning is not given justice by the researchers in the field of urban studies. Sustainable compact city planning concept is discussed in fragments only so far. Therefore, a new methodology is evolved and proposed in this paper to develop a holistic sustainable compact city. 


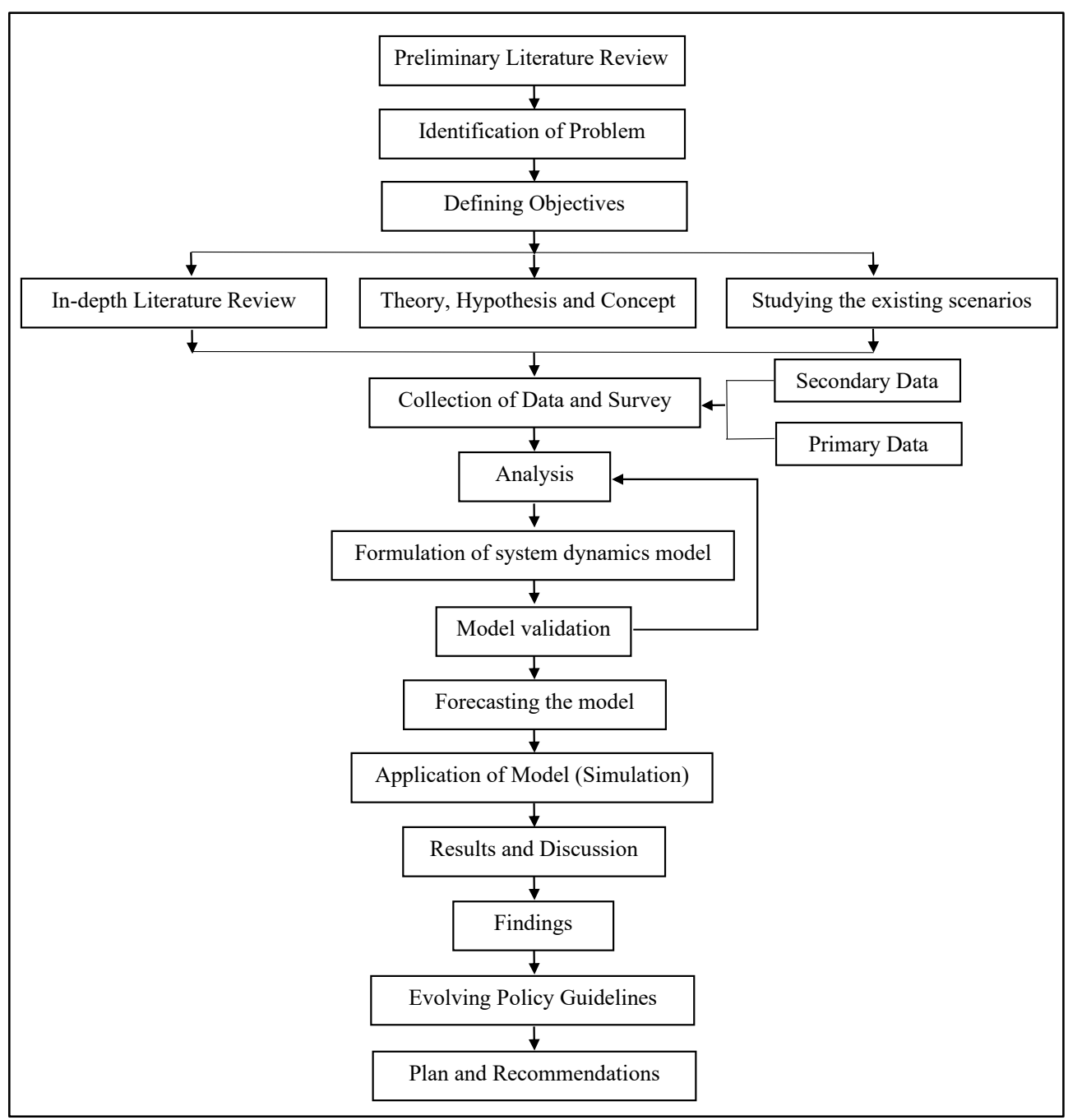

Figure 3: Proposed optimal methodology. (Source: Authors, 2020.)

There are various limitations in research related to sustainable compact city planning. Literature show that there is no definition for sustainable compact city available. There is a lack of guidelines for sustainable compact city planning. Lack of data availability with respect to the various subsystems namely physical, social, economic, ecological, environmental, institutional, and infrastructure of the urban system is a major limitation. The literature review clearly indicates that there is no holistic methodology available for sustainable compact city planning. In Indian context, there is no exemplary or model city is developed by using sustainable compact city concept. The present investigation proposes a new methodology for evolving sustainable compact city plan. It is a theoretical conceptualisation with system concept input. If the proposed methodology is employed while planning, and execution is done judiciously, sustainable compact city would be anticipated. 


\section{REFERENCES}

[1] Dantzig, G.B. \& Saaty, T.L., Compact City: A Plan for a Liveable Urban Environment, W.H. Freeman: San Francisco, 1973.

[2] Holman, N., Mace, A., Paccoud, A. \& Sundaresan, J., Coordinating density: Working through conviction, suspicion and pragmatism. Progress in Planning, 101, pp. 1-38, 2015.

[3] Harwood, R., A history of sustainable agriculture. Sustainable Agricultural Systems, eds C.A. Edwards, R. Lal, P. Madden, R.H. Miller \& G. House, Soil and Water Conservation Society: Ankeny, pp. 3-19, 1990.

[4] Pearce, D.W., Barbier, E.B., Markandya, A. \& Barbier, E., Blueprint for a Green Economy, Earthscan: London, 1989.

[5] Conway, G.R. \& Barbier, E.B., After the Green Revolution: Sustainable Agriculture for Development, Earthscan: London, 1990.

[6] Pearce, D.W. \& Atkinson, G.D., Capital theory and the measurement of sustainable development: an indicator of "weak" sustainability. Ecological Economics, pp. 103108, 1993.

[7] World Commission on Environment and Development (WCED), Our Common Future, Oxford University Press: Oxford, 1987.

[8] Boyko, C. \& Cooper, R., Clarifying and re-conceptualising density. Progress in Planning, 76(1), pp. 1-61, 2011.

[9] Shammin, M.R., Herendeen, R.A., Hanson, M.J. \& Wilson, E., A multivariate analysis of the energy intensity of sprawl versus compact living in the U.S. for 2003. Ecological Economics, 69(12), pp. 2363-2373, 2010.

[10] Chhetri, P., Han, J.H., Chandra, S. \& Carcoran, J., Mapping urban residential density patterns: Compact city model in Melbourne, Australia. City, Culture and Society, 4(2), pp. 77-85, 2013.

[11] Williams, K., Urban intensification policies in England: Problems and contradictions. Land Use Policy, 16(3), pp. 167-178, 1999.

[12] Burton, E., The compact city: Just or just compact? A preliminary analysis. Urban Studies, 37(11), pp. 1969-2001, 2000.

[13] Knox, P., Cities and Design, Routledge: New York, 2011.

[14] Combes, P., Duranton, G., Gobillon, L. \& Roux, S., Estimating agglomeration economies with history, geology, and worker effects. Agglomeration Economics, ed. E.L. Glaeser, Chicago University Press: Chicago, pp. 15-66, 2010.

[15] Churchman, A., Disentangling the concept of density. Journal of Planning Literature, 13(4), pp. 389-411, 1999.

[16] Ahlfeldt, G.M. \& McMillen, D.P., The Vertical City: The Price of Land and the Height of Buildings in Chicago 1870-2010, Spatial Economics Research Centre (LSE): London, 2015.

[17] Hilber, C. \& Cheshire, P., Office space supply restrictions in Britain: The political economy of market revenge. The Economic Journal, 118(529), pp. 185-221, 2008.

[18] Neuman, M., The compact city fallacy. Journal of Planning Education and Research, 25(1), pp. 11-26, 2005.

[19] Beer, A., Spatial inequality and locational disadvantage. Urban Policy and Research, 12(3), pp. 181-199, 1994.

[20] Dieleman, F. \& Wegener, M., Compact city and urban sprawl. Built Environment, 30(4), pp. 308-323, 2004. 
[21] Carruthers, J.I. \& Ulfarsson, G.F., Urban sprawl and the cost of public services. Environment and Planning B: Planning and Design, 30(4), pp. 503-522, 2003.

[22] Matsumoto, T., Compact city policies: Comparative assessment. Presented at 47th ISOCARP Congress, Wuhan, China, 2011.

[23] Troy, P., The Perils of Urban Consolidation: A Discussion of Australian Housing and Urban Development Policies, The Federation Press: Sydney, 1996.

[24] Bonfantini, B., Centri storici: Infrastrutture per l'urbanità contemporanea. Territorio, 64, pp. 153-161, 2013.

[25] Radberg, J., Towards a theory of good urban form. Presented at 14th Conference of the International Association for People Environment Studies, Stockholm, Sweden, 1996.

[26] Braga, A.A. \& Weisburd, D.L., Policing Problem Places: Crime Hot Spots and Effective Prevention, Oxford University Press: Oxford and New York, 2010.

[27] Tang, C., Urban Structure and Crime, London School of Economics: London, 2015.

[28] Jacobs, J., The Death and Life of Great American Cities, Random House: New York, 1961.

[29] Welsh, B. \& Farrington, D., Effects of Closed Circuit Television Surveillance on Crime, The Campbell Collaboration, 2008, p. 17, 2008.

[30] Wolsink, M., "Sustainable City" requires "recognition": The example of environmental education under pressure from the compact city. Land Use Policy, 52, pp. 174-180, 2016.

[31] Bechle, M.J., Millet, D.B. \& Marshall, J.D., Effects of income and urban form on urban $\mathrm{NO}_{2}$ : Global evidence from satellites. Environmental Science and Technology, 45(11), pp. 914-919, 2011.

[32] Gordon, P.\& Richardson, H.W., Are compact cities a desirable planning goal? Journal of the American Planning Association, 63(1), pp. 95-106, 1997.

[33] Russo, A. \& Cirella, G.T., Modern compact cities: How much greenery do we need? International Journal for Environmental Research and Public Health, 15(10), pp. 120, 2018.

[34] Chang, H. \& Chen, T., Examine sustainable urban space based on compact city concept. Global Journal of Human-Social Science: B Geography, Geo-Sciences, Environmental Science and Disaster Management, 16(4), pp. 1-11, 2016.

[35] Masnavi, R., Measuring urban sustainability: Developing a conceptual framework for bridging the gap between theoretical levels and the operational level. International Journal for Environmental Research, 1(2), pp. 188-197, 2007.

[36] Chen, H., Jia, B. \& Lau, S., Sustainable urban form for Chinese compact cities: Challenges of rapid urbanized economy. Habitat International, 32(1), pp. 28-48, 2008.

[37] Coorey, S. \& Lau, S., Urban compactness and its progress towards sustainability: The Hong Kong scenario. WIT Transactions on Ecology and the Environment, vol. 84, WIT Press: Southampton and Boston, pp. 87-97, 2005.

[38] Lin, J. \& Yang, A., Does the compact-city paradigm foster sustainability? An empirical study in Taiwan. Environment and Planning B: Planning and Design, 33, pp. 365$380,2006$.

[39] Devadas, V. \& Kumar, N., Integrated urban development plan: A scientific approach. Journal of Indian Building Congress, 16(1), pp. 35-42, 2007. 